\title{
sciendo
}

\author{
Current Issues in Pharmacy and Medical Sciences \\ Formerly ANNALES UNIVERSITATIS MARIAE CURIE-SKLODOWSKA, SECTIO DDD, PHARMACIA \\ journal homepage: http://www.curipms.umlub.pl/
}

\section{Gingival health in children in the different phases of acute lymphoblastic leukemia}

\author{
Luidmyla F. Kaskova $\bullet$, Natalita V. Yanko ${ }^{\star}$, Irena Y. Vashchenko® \\ Department of Pediatric Therapeutical Dentistry with Prevention of Stomatological Diseases, Ukrainian Medical Stomatological Academy,
} Schevchenko 23, 36011, Poltava, Ukraine

\section{ARTICLE INFO}

Received 07 December 2018

Accepted 11 April 2019

\section{Keywords:}

acute lymphoblastic leukemia, children,

gingivitis,

gingival indices.

\begin{abstract}
Acute lymphoblastic leukemia (ALL), the most common type of leukemia in children, has diverse oral cavity complications. While periodontal alterations in such patients are widely known, there were no studies evaluating gingival health from the time of diagnosis to the remission phase. In our study, we, therefore, analysed the frequency of periodontal diseases and the gingival indices in the different phases of ALL in children. Children aged 7-15 years were involved into the cross-sectional study. Therein, 160 children with ALL were divided into three groups: L1 - 50 children examined before the initiation phase, L2 - 50 children examined after 1 month of the chemotherapy, L3 - 60 children examined in permanent hematologic remission. The control (HC) included 150 healthy children. The L1, L2 and L3 groups had significantly worse gingival indices and frequency of gingivitis than the HC group $(\mathrm{p}<0.0001)$. Frequency of gingivitis increased from before the initiation to the remission phase, but significantly only in $7-11$ year-old children $(p=0.0004)$. Gingival indices increased after 1 month of chemotherapy $(p<0.0001)$, but decreased in the permanent remission phase $(\mathrm{p}<0.0001)$.

Our study stresses the need for children with ALL to not only require prevention courses before the initiation and during the chemotherapy phases, but also in the permanent remission phase to minimize the long-term impact of leukemia treatment on gingival health.
\end{abstract}

\section{INTRODUCTION}

The effect of systemic diseases on the dental state has been studied from ancient [1,2] to modern times [3-5]. Indeed, often times it was and is the dentist who first suspects a severe systemic disease and guides a patient to a specialist. In the last decade there has been a growth both in cancer morbidity and survival rate [6], therefore, quality of life of such patients has become one of the major medical problems. ALL is considered the most common type of leukemia in children and holds a variety of oral cavity complications.

Periodontal alterations in patients with leukemia are attributed to hematologic disorders [7] or are associated with chemotherapy and radiation therapy [8,9]. They can be noted at the early stage of leukemia [10], during chemotherapy [11], and during maintenance phases [12]. Despite the fact

\footnotetext{
* Corresponding author

e-mail: latned@ukr.net
}

that the late effects of leukemia treatment on gingival health have described in few articles [13-17], there were no studies evaluating gingival health from the time of diagnosis to the permanent remission phase.

This study is aimed at analysing the frequency of periodontal diseases and at establishing the gingival indices in the different phases of ALL in children.

\section{MATERIALS AND METHODS}

The cross-sectional study involves 373 children aged 7-15 years. All children in the study group were examined by one investigator. Among the 373 subjects, 213 healthy individuals formed the control group (group HC). Of these, 110 were males and 103 were females. A total of 160 children ( 83 males and 77 females) who had been diagnosed with ALL and were already undergoing different phases of intensive chemotherapy were selected for the study. The children underwent dental examination in the Pediatric Hematology 
Ward of Chidren's Hospital (Poltava, Ukraine). Patient selection was based on the following criteria:

1. patients were newly diagnosed with ALL;

2. the aims and requirements of the study were freely accepted by the parents;

3. the recruitment, follow-up and compliance of patients;

4. patients with any systemic disease except ALL were excluded.

Patients with ALL were categorized into three groups. Group L1 - 50 patients examined before the initiation therapy, group L 2 - 50 patients examined after 1 month of the chemotherapy; group L3 - 60 patients examined while in permanent hematologic remission (1-5 years). Patients received hematologic treatment according to ALL-BMFREZ-95 and ALL-BMF-REZ-2002 protocols. The HC and L groups were divided into 2 subgroups: 7-11 years old and $12-15$ years old. We enrolled 63 boys and 59 girls aged between 7-11 years of age in the HC group. Ethical approval was obtained from the Ethical Committee of Ukrainian Medical Stomatological Academy, and informed consent was obtained from all the study subjects (their parents). The children were instructed to clean their teeth with a soft brush, and rinse their mouths with the herbal mouthwash (Phytodent), but most children refused to clean their teeth in the chemotherapy phase due to strong gum bleeding.

Periodontal examination was performed in compliance with the guidelines for periodontal screening [18]. Frequency of gingivitis and periodontitis was evaluated. In addition, the assessment of gingival inflammation was performed by Silness-Loe index [19], papilla-marginal index (PMA) modified by Parma [20] and papilla bleeding index (PBI) introduced by Saxer and Muhlemann [21]. A periodontal probe was used for Silness-Loe and PBI indices (AEP WHO B; Hu-Friedy).

Categorical variables were analysed by Fisher's exact test. Statistical significance level of $\mathrm{p} \leq 0.05$ was applied for all calculations.

\section{RESULTS}

Groups L1, L2, L3 had significantly worse gingival indices than group $\mathrm{HC}(\mathrm{p}<0.0001)$ both in $7-11$ years-old (Table 1) and in 12-15 years-old children (Table 2).

Gingival enlargement with spontaneous bleeding or bleeding on tooth brushing was revealed in group L1. Patients of group L2 demonstrated a high rate of necrotic, sloughing, gingival tissue with moderate erythema and multiple ulcerations. In HC and L3 groups, gingival enlargement without spontaneous bleeding dominated. One third of all 12-15 years-old children in the remission phase had multiple pockets, mostly $<4 \mathrm{~mm}$.

The changes in the gingival indices represented intensity of gum inflammation in the different phases of ALL. In the 7-11 years-old children from group L2, these indices were significantly higher (Table 1) than that in group L1 $(p<0.0001)$. In the children from group L3, a significant decrease as compared to L2 group was found for all examined gingival indices $(\mathrm{p}<0.0001)$.

The 12-15 years-old children from group L1 (Table 2) had significantly higher gingival indices than did their healthy counterparts $(\mathrm{p}<0.001)$ (Table 2$)$. These indices were also significantly higher in group L2 than in group L1 $(\mathrm{p}<0.001)$. There was significant decrease in all gingival indices in $12-15$ years-old children $(p<0.0001)$ from the L3 group, as compared to the L2 group.

Table 1. The gingival indices in 7-11 years-old children in different phases of acute lymphoblastic leukemia

\begin{tabular}{|c|c|c|c|c|}
\hline Group & $\begin{array}{c}\text { Number } \\
\text { of examined }\end{array}$ & $\begin{array}{c}\text { PMA } \\
\%\end{array}$ & $\begin{array}{c}\text { Silness-Loe } \\
\text { scores }\end{array}$ & $\begin{array}{c}\text { PBI } \\
\text { scores }\end{array}$ \\
\hline HC & 122 & $5.83 \pm 0.56$ & $0.3 \pm 0.07$ & $0.27 \pm 0.04$ \\
\hline L1 & 28 & $16.71 \pm 2.7$ & $0.85 \pm 0.05$ & $1.45 \pm 0.07$ \\
\hline L2 & 28 & $35.6 \pm 4.0$ & $2.1 \pm 0.11$ & $3.5 \pm 0.15$ \\
\hline L3 & 30 & $28.9 \pm 2.9$ & $1.6 \pm 0.13$ & $1.5 \pm 0.11$ \\
\hline
\end{tabular}
of chemotherapy, L3 - the remission phase

Table 2. The gingival indices in 12-15 years-old children in different phases of acute lymphoblastic leukemia

\begin{tabular}{|c|c|c|c|c|}
\hline Group & $\begin{array}{c}\text { Number } \\
\text { of examined }\end{array}$ & $\begin{array}{c}\text { PMA } \\
\%\end{array}$ & $\begin{array}{c}\text { Silness-Loe } \\
\text { scores }\end{array}$ & $\begin{array}{c}\text { PBI } \\
\text { scores }\end{array}$ \\
\hline HC & 91 & $6.0 \pm 0.84$ & $0.73 \pm 0.06$ & $0.32 \pm 0.12$ \\
\hline L1 & 22 & $28.4 \pm 3.2$ & $1.5 \pm 0.12$ & $2.2 \pm 0.08$ \\
\hline L2 & 22 & $41.6 \pm 3.04$ & $2.3 \pm 0.14$ & $3.6 \pm 0.14$ \\
\hline L3 & 30 & $26.08 \pm 4.01$ & $1.87 \pm 0.02$ & $1,2 \pm 0,2$ \\
\hline
\end{tabular}
HC - healthy controls; L1 - before the initiation phase, L2 - after 1 month of chemotherapy, L3 - the remission phase

The Frequency of gingivitis in 12-15 years-old healthy children (Table 4) was higher than in 7-11 years-old children (Table 3$)(p=0.0005)$. In addition, the frequency of gingivitis in 7-11 years-old children and 12-15 years-old children was higher in groups L1, L2, L3 $(p<0.0001)$ than in group $\mathrm{HC}$, and increased over the course of disease. What is more, periodontitis was revealed in 12-15 years-old children from group L3 (Table 4). Total frequency of periodontal diseases was significantly higher in group L3 than in group L2 in 7-11 years-old children $(\mathrm{p}<0.0001)$ (Table 3$)$ and insignificantly so in 12-15 years-old children ( $\mathrm{p}>0.1)$ (Table 4$)$.

Table 3. The gingivitis frequency in 7-11 years-old children in different phases of acute lymphoblastic leukemia

\begin{tabular}{|c|c|c|c|}
\hline Groups & $\begin{array}{c}\text { Number } \\
\text { of examined }\end{array}$ & $\begin{array}{c}\text { Number of children } \\
\text { with gingivitis }\end{array}$ & $\begin{array}{c}\text { Frequency } \\
\text { of gingivitis, \% }\end{array}$ \\
\hline HC & 122 & 25 & $20.5 \pm 3.6$ \\
\hline L1 & 28 & 13 & $46.9 \pm 9.4$ \\
\hline L2 & 28 & 22 & $78.6 \pm 7.7$ \\
\hline L3 & 30 & 27 & $90.0 \pm 5.4$ \\
\hline
\end{tabular}

HC - healthy controls; L1 - before the initiation phase, L2 - after 1 month of chemotherapy, L3 - the remission phase

Table 4. The periodontitis frequency in 12-15 years-old children in different phases of acute lymphoblastic leukemia

\begin{tabular}{|c|c|c|c|c|c|c|}
\hline Groups & 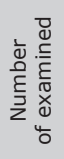 & 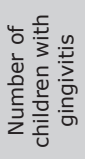 & 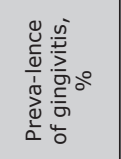 & 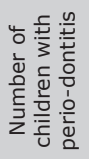 & 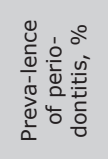 & 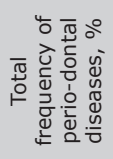 \\
\hline $\mathrm{HC}$ & 91 & 39 & $42.8 \pm 5.2$ & - & - & $42.8 \pm 5.2$ \\
\hline L1 & 22 & 18 & $81.8 \pm 8.2$ & - & - & $81.8 \pm 8.2$ \\
\hline L2 & 22 & 20 & $91.0 \pm 6.3$ & - & - & $91.0 \pm 6.3$ \\
\hline L3 & 30 & 19 & $63.3 \pm 10.2$ & 10 & $33.3 \pm 8.6$ & $96.6 \pm 3.3$ \\
\hline
\end{tabular}

HC - healthy controls; L1 - before the initiation phase, L2 - after 1 month of chemotherapy, L3 - the remission phase 
The results evidenced in Table 3 reveal there was significant increase in frequency of gingivitis in 7-11 years-old children from the L2 group $(p=0.01)$ and from the L3 group ( $\mathrm{p}=0.0004)$, as compared to the L1 group. In the 12-15 years-old children from the L2 group, frequency of gingivitis increased nonsignificantly, as compared to the L1 group $(p=0.31)$. Finally, insignificant increases in frequency of gingivitis in the L3 group, as compared with the L2 group were found in both subgroups ( $p>0.2)$ (Table 3 and 4).

\section{DISCUSSION}

The results exhibit significant increases $(p<0.0001)$ in gingival indices in the L1, L2 and L3 patient groups when compared with the healthy group - as showed in Tables 1 and 2. Results close to these in the presented study were obtained by Pels and Mielnik-Błaszczak (2012), who demonstrated that Silness-Loe gingival index was significantly higher in children with ALL before chemotherapy than in healthy children [22]. The study of Sonis et al. (1995) showed that children prior to age 5 years with ALL who were treated with chemotherapy and radiotherapy and were at least 5 years in continuous remission had significantly higher modified gingival index scores than did healthy children [13]. In a study by Avzar et al. (2007) of childhood cancer survivors who were in remission from 0,5 to 7,2 years, significantly higher gingival index was found, compared to their healthy counterparts [17]. These changes probably resulted from the decreased immunity of the leukemia afflicted children and the cytotoxic effect of chemotherapy.

Dens et al. (1995), however, claimed that gingival index scores were the same in long-term survivors of pediatric malignancies and in healthy children [14]. The following points have to be taken into account: in that research only a half of the examined children had ALL, average length of remission was 9 years and age of children was from 2 to 17 years. A normal gingival index was found by Welbury et al. (1984) in children/young adults aged from 3 to 20 years who had ALL or solid tumours and were in long remission (duration was not mentioned) [15]. We hypothesize that the normal values of gingival index in these studies might have been influenced by the variation of cancer pathologies, the great age difference and the duration of remission.

The results revealed in Tables 1 and 2 demonstrate that there were significant increases $(p<0.0001)$ in gingival indices in children after 1 month of the chemotherapy course. This study agrees with the finding of Azher and Shiggaon (2013) who reported that the modified gingival index in children with ALL aged 2-14 years was higher in the maintenance phase of the chemotherapy than in the induction phase [12]. Dholam et al. (2014) claimed that Silness-Loe index worsened in acute leukemic pediatric patients aged 5-15 years following first induction chemotherapy [23].

The current results are in disagreement with the study of Pels and Mielnik-Błaszczak (2012) who showed that children with ALL aged 2-18 years had better gingival index during chemotherapy than before chemotherapy as result of the regulated oral hygiene regime with two mouthwashes [22].
Unfortunately, in previous studies, patients were not followed up from the time of diagnosis to the remission phase. In the present study, Silness-Loe, modified PMA index and PBI results showed significantly decrease in the remission phase as compared to the chemotherapy phase $(\mathrm{p}<0.0001)$. Of note, periodontal pockets were found in one third of 12-15 years-old children in the remission.

A natural peak prevalence of gingivitis has been determined in females and males with the onset of puberty [24, 25]. Still, taking this into account, frequency of gingivitis was higher in 12-15 years-old healthy children (Table 4) than in 7-11 years-old children (Table 3$)(p=0.0005)$.

Due to significant difference in the gingivitis frequency between patients with ALL and their healthy peers $(\mathrm{p}<0.001)$, we hypothesize that ALL and its chemotherapy accelerate periodontal diseases. Significant increase in frequency of gingivitis in the chemotherapy phase $(p=0.01)$ and in the remission phase $(p=0.0004)$ as compared to before the initiation phase was found in 7-11 year-old children (Table 3 ). Insignificant increases in frequency of gingivitis between different phases of ALL were found in the 12-15 years old subgroup $(p>0.2)$ because of the high rate of gingivitis in HC and L1 groups (Table 4).

Future research may develop a novel strategy for the periodontal disease prevention in patients with ALL based on the pathogenesis of periodontal alterations.

\section{CONCLUSIONS}

Children with ALL from the before initiation to the permanent remission phase had significantly worse gingival health than did their healthy counterparts. Frequency of gingivitis also deteriorated over the clinical course of disease, whereas gingival indices increased after 1 month of chemotherapy and decreased in the permanent remission phase. Taking all these aspects into consideration, it can be concluded that children with ALL not only require prevention courses before the initiation and during the chemotherapy phases, but in the permanent remission phase to minimize the long-term impact of leukemia treatment on gingival health. This is a future task for health-promotion research.

\section{ORCID iDs}

Luidmyla Fedorivna Kaskova

Nataliia Valentinovna Yanko

Dhttps://orcid.org/0000-0003-0855-2865

Irena Yurievna Vashchenko

(Dhttps://orcid.org/0000-0002-3752-4110

(Dhttps://orcid.org/0000-0002-5025-8005

\section{REFERENCES}

1. Kas'kova LF, Artem'ev AV, Berezhnaia EE, Amosova LI. Features' dental status population of the territory of Ukraine in different historical epochs. Georgian Med News. 2014;237:35-40.

2. Yanko NV, Artemyev AV, Kaskova LF. Frequency of dental caries in children in the Early Iron Age and the Medieval populations from Ukraine. Antrop Rev. 2017;80(4):415-26.

3. Kim J, Ama S. Periodontal disease and systemic conditions: a bidirectional relationship. Odontology. 2006;94(1):10-21.

4. Nazaryan R, Kryvenko L. Salivary oxidative analysis and periodontal status in children with atopy. Interv Med Appl Sci. 2017;9(4):199-203. 
5. Arigbede AO, Babatope BO, Bamidele MK: Periodontitis and systemic diseases: A literature review. J Indian Soc Periodontol. 2012;16(4):487-91.

6. Hunger SP, Lu X, Devidas M, Camitta BM, Gaynon PS, Winick NJ et al. Improved survival for children and adolescents with acute lymphoblastic leukemia between 1990 and 2005: a report from the children's oncology group. J Clin Oncol. 2012;30(14):1663-69.

7. Lauritano D, Petruzzi M, Fumagalli T, Giacomello MS, Caccianiga G. Oral manifestations in children with acute lymphoblastic leukemia. Eur J Inflamm. 2012;10(2):65-8.

8. Padmini C, Bai KY. Oral and Dental Considerations in Pediatric Leukemic Patient. ISRN Hematology. 2014; Article ID 895721:11 pages. https://doi.org/10.1155/2014/895721.

9. Francisconi CF, Caldas RJ, Martins LJO, Fischer Rubira CM, da Silva Santos PS. Leukemic oral manifestations and their management. Asian Pac J Cancer Prev. 2016;17:911-5.

10. Rinčić N, Božić D, Rinčić G, Gaćina P, Plančak D. Evaluation of Periodontal Parameters in Patients with Early Stage Chronic Lymphocytic Leukemia. Acta Stomatol Croat. 2016;50(1):23-33.

11. Oliveira MC, Borges TS, Miguens SAQ, Gasse HT, Fontanella VC. Oral manifestations in pediatric patients receiving chemotherapy for leukemia. Stomatos. 2016;22(43):20-30.

12. Azher U, Shiggaon N. Oral health status of children with acute lymphoblastic leukemia undergoing chemotherapy. Indian J Dent Res. 2013;24(4):523.

13. Sonis AL, Waber DP, Sallan S, Tarbell NJ. The oral health of long term survivors of acute lymphoblastic leukemia: a comparison of three treatment modalities. Eur J Cancer B Oral Oncol. 1995;31B(4):250-2.

14. Dens F, Boute P, Otten J, Vinckier F, Declerck D. Dental caries, gingival health, and oral hygiene of long term survivors of paediatric malignant diseases. Arch Dis Child. 1995;72(2):129-32.
15. Welbury RR, Craft AW, Murray JJ, Kernahan J. Dental health of survivors of malignant disease. Arch Dis Child. 1984;59(12):1186-87.

16. Nemeth O, Hermann P, Kivovics P, Garami M. Long-term effects of chemotherapy on dental status of children cancer survivors. Pediatr Hematol Oncol. 2013;30(3):208-15.

17. Avşar A, Elli M, Darka O, Pinarli G. Long-term effects of chemotherapy on caries formation, dental development, and salivary factors in childhood cancer survivors. Oral Surg Oral Med Oral Pathol Oral Radiol Endod. 2007;104(6):781-9.

18. Guidelines for periodontal screening and management of children and adolescents under 18 years of age. Retrieved from https://www. bsperio.org.uk/publications/downloads/ 54_090016_bsp_bspdperio-guidelines-for-the-under-18s-2012.pdf.

19. Löe H, Silness J. Periodontal disease in pregnancy. Acta Odontol Scand. 1963;21:533-51.

20. Parma C. Parodontopathien. Leipzig: I.A.Verlag; 1978: p. 203.

21. Saxer UP, Mühlemann HR. Motivation and education. Schweiz Monatsschr Zahnheilkd. 1975;85(9):905-919.

22. Pels E, Mielnik-Błaszczak M. Oral hygiene in children suffering from acute lymphoblastic leukemia living in rural and urban regions. Ann Agric Environ Med. 2012;19(3):529-533.

23. Dholam KP, Gurav S, Dugad J, Banavli S. Correlation of oral health of children with acute leukemia during the induction phase. Indian J Med Paediatr Oncol. 2014;35:36-39.

24. Nakagawa S, Fujii H, Machida Y, Okuda K. A longitudinal study from prepuberty to puberty of gingivitis. J Clin Periodontol. 1994; 21:658-65.

25. Marcuschamer E, Hawley CE, Speckman I, Romero RM, Molina JN. A lifetime of normal hormonal events and their impact on periodontal health. Perinatol Reprod Hum. 2009;23:53-64. 